\title{
Comparison of The 7th and 8th Editions of The Union for International Cancer Control /American Joint Committee on Cancer Staging System for Nonmetastatic Nasopharyngeal Carcinoma in The Intensity-Modulated Radiotherapy Era
}

\section{Tao He}

Department of Head and Neck Oncology, Cancer Center, State Key Laboratory of Biotherapy, West China Hospital, Sichuan University, Chengdu, Sichuan

\section{Ruo-Nan Yan}

Department of Head and Neck Oncology, Cancer Center, State Key Laboratory of Biotherapy, West China Hospital, Sichuan University, Chengdu, Sichuan

\section{Hua-Ying Chen}

Department of Head and Neck Oncology, Cancer Center, State Key Laboratory of Biotherapy, West China Hospital, Sichuan University, Chengdu, Sichuan

\section{Yuan-Yuan Zeng}

Department of Head and Neck Oncology, Cancer Center, State Key Laboratory of Biotherapy, West China Hospital, Sichuan University, Chengdu, Sichuan

\section{Zhong-Zheng Xiang}

Department of Head and Neck Oncology, Cancer Center, State Key Laboratory of Biotherapy, West China Hospital, Sichuan University, Chengdu, Sichuan

\section{Fang Liu}

Department of Head and Neck Oncology, Cancer Center, State Key Laboratory of Biotherapy, West China Hospital, Sichuan University, Chengdu, Sichuan

\section{Bian-Fei Shao}

Department of Head and Neck Oncology, Cancer Center, State Key Laboratory of Biotherapy, West China Hospital, Sichuan University, Chengdu, Sichuan

Jia-Chun Ma

Department of Head and Neck Oncology, Cancer Center, State Key Laboratory of Biotherapy, West China Hospital, Sichuan University, Chengdu, Sichuan

\section{Xi-Ran Wang}

Department of Head and Neck Oncology, Cancer Center, State Key Laboratory of Biotherapy, West China Hospital, Sichuan University, Chengdu, Sichuan

Lei Liu ( $\square$ liuleihx@gmail.com ) 
Department of Head and Neck Oncology, Cancer Center, State Key Laboratory of Biotherapy, West China Hospital, Sichuan University, Chengdu, Sichuan

\section{Research Article}

Keywords: Nasopharyngeal carcinoma, Simultaneous integrated boost, Intensity-modulated accelerated radiotherapy, AJCC/UICC staging system, Prognosis, Radiotherapy

Posted Date: November 24th, 2020

DOl: https://doi.org/10.21203/rs.3.rs-107939/v1

License: (c) (1) This work is licensed under a Creative Commons Attribution 4.0 International License. Read Full License

Version of Record: A version of this preprint was published at BMC Cancer on March 30th, 2021. See the published version at https://doi.org/10.1186/s12885-021-08036-8. 


\section{Abstract}

Background: To compare the prognostic value of 7th and 8th editions of the Union for International Cancer Control /American Joint Committee on Cancer (AJCC) staging system for patients with nonmetastatic nasopharyngeal carcinoma (NPC) treated with intensity-modulated radiotherapy and simultaneous integrated boost- intensity-modulated radiation therapy (SIB-IMRT).

Methods: Patients with NPC $(n=300)$ who received SIB-IMRT were included. Survival by T-classification, $\mathrm{N}$-classification, and stage group of each staging system was assessed.

Results: For T-classification, nonsignificant difference was observed between T1 and T2 and between T2 and T3 disease ( $P=0.066$ and 0.106 , respectively) for overall survival (OS) in the 7th staging system, whereas all these differences were significant in the 8th staging system (all $P<0.05$ ). The survival curves for disease-free survival (DFS) and LRFS in both staging systems were similar, except for the comparison of T2 and T4 disease for LRFS ( $P=0.07$ for 7th edition; $P=0.011$ for 8th edition). For N-classification, significant differences were observed between N2 and N3 diseases after revision $(P=0.046$ and $P=$ 0.043 for OS and DFS, respectively). For staging system, no significant difference was observed between IVA and IVB of 7th edition.

Conclusion: The 8th AJCC staging system appeared to have superior prognosis value in the SIB-IMRT era compared with the 7th edition.

\section{Introduction}

Nasopharyngeal carcinoma (NPC) develops in the epithelial lining of the nasopharynx, the narrow tubular passage behind the nasal cavity, and radiation therapy (RT) is the primary treatment because of anatomical constraints and high radiosensitivity of this carcinoma.

Over the past 2 decades, NPC management has undergone substantial changes. Magnetic resonance imaging (MRI), which has been widely used in the clinical staging of NPC, has made it possible to define tumour volume precisely and allow the early detection of occult metastases [1-3]. In terms of disease modality, intensity-modulated radiation therapy (IMRT) could decrease the overall treatment time and increase the fractionation dose to planned target volume (PTV) with relatively less late toxicity compared with 2-dimensional conventional or 3-dimensional conformal radiotherapy [4-8]. Therefore, the new staging system should be based on up-to-date clinical data and maintain its relevance with current management approaches.

The classification of N3 in the 7th edition of the Union for International Cancer Control /American Joint Committee on Cancer (UICC/AJCC) NPC staging system is mainly based on anatomy, and its ability to predict prognosis is limited $[9,10]$. The UICC/AJCC released the 8th edition of this staging system in an attempt to further help clinicians opt for the best treatment for patients. The revised staging system was mainly derived from a study on 1609 patients with NPC on the basis of their MRI findings and IMRT 
status [11]. A few key revisions in the $8^{\text {th }}$ edition are as follows: (1) for T-classification, patients with infratemporal fossa/masticator space involvement, which was considered in the T4 category in the 7th edition, has been replaced with a precise definition; (2) medical pterygoid (MP) and lateral pterygoid (LP) muscles have been downgraded to the T2 category, whereas prevertebral muscles have been included in the T2 category; (3) For the N-classification, the supraclavicular fossa (SCF) has been replaced by the caudal border of the cricoid cartilage, and N3a and N3b in the 7th edition have been reclassified to N3; (4) T4 and N3 have been merged into IVA; (5) For the clinical stage, stages IVA and IVB in the 7th edition have been redefined as IVA, and stage IVC has been reclassified as IVB in the 8th edition. Table 1 shows the classification criteria of the 7th and 8th editions of the UICC/AJCC nasopharyngeal carcinoma staging system.

Patients with NPC can receive IMRT via 2 push modes: the conventional sequential boost and simultaneous integrated boost. Compared with the conventional method, SIB-IMRT can be delivered in different target regions during the same treatment session and has a shorter waiting time. In addition, most clinical data revealed that SIB-IMRT had better sparing of the parotid glands and inner ear structures $[12,13]$.

We performed this retrospective study to explore the clinical outcomes of SIB-IMRT, and compare the 7th and 8th editions of the UICC/AJCC staging system.

\section{Materials And Methods}

\section{Patient characteristics}

A total of 300 patients with newly diagnosed, pathologically proven, non-distant metastatic NPC who were treated with SIB-IMRT at West China Hospital between February 2009 and December 2013 were included in our study. Table 2 summarises the characteristics of all the patients. All the patients had no tumour history and did not receive any radiotherapy previously. The number of men was $215(71.7 \%)$, whereas the number of women was 85 (28.3\%). Median age was 47 years (range, 11-81 years). All patients were underwent the following pretreatment evaluations: recording of completed patient history, haematological and biochemical profiles, physical examination, flexible fiberoptic endoscopic examination, MRI of the nasopharynx and neck, abdominal sonography, chest radiography or $\mathrm{CT}$, and whole-body bone scan. All the patients were reclassified according to the 7th and 8th editions of the UICC/AJCC staging system by 2 clinicians. A third clinician was consulted to reach a consensus in case of disagreement.

\section{RT}

All patients completed radical SIB-IMRT at the Tumor Center of West China hospital according to the guidelines for RT based on reduced volume IMRT [14]. RT 
is carried out in accordance with the guidelines of NCCN radiotherapy for NPC. The primary nasopharynx gross tumour volume (GTVnx) and metastatic cervical lymph nodes (GTVnd) included all gross diseases observed in the MRI scan (GTVnx and GTVnd are usually referred to as 2 MRI scans of patients obtained before and after induction chemotherapy). CTV-1 was defined as a high-risk region that included the primary nasopharynx tumour volume with a 5-10 mm margin and the entire nasopharynx. CTV-2 was defined as potentially involved region that included the skull base, pterygopalatine fossa, pterygoid processes, anterior third of the clivus and cervical vertebra, inferior sphenoid sinus and cavernous sinus, nasopharyngeal cavity (including the posterior region of the nasal cavity), maxillary sinus ( $5 \mathrm{~mm}$ anterior to the maxillary mucosa and posterior nares), posterior ethmoid sinus, parapharyngeal space, and bilateral retropharyngeal lymph nodal regions. The clinical target volume of the neck node regions (CTVN) covered Levels II, III, IV, and V, according to the recommendation of the Radiation Therapy Oncology Group (RTOG)/European Organisation for Research and Treatment of Cancer delineation consensus. SIBIMRT was administered for one month after the patients completed induction chemotherapy. The radiation doses delivered were 70 Gy to GTVnx and GTVnd in 33 fractions at 2.12 Gy per fraction, 60 Gy at 2Gy per fraction to CTV-1, and 56 Gy to CTV-2 and CTV-N in 33 fractions, 5 times per week.

\section{Chemotherapy}

A total of 173 patients received both induction chemotherapy and concurrent chemotherapy (cisplatin 80 $\mathrm{mg} / \mathrm{m}^{2}$ divided into 3 parts on days $1-3$, every 3 weeks). The main induction chemotherapy regimen was TPF (paclitaxel $135 \mathrm{mg} / \mathrm{m}^{2}$ day 1 , cisplatin $80 \mathrm{mg} / \mathrm{m}^{2}$ divided into 3 parts on days $1-3$, and fluorouracil $750 \mathrm{mg} / \mathrm{m}^{2}$ per day on days $1-5$, every 3 week). Of the total, 67 patients received only concurrent chemotherapy and 42 patients received concurrent chemotherapy along with the adjuvant chemotherapy, and the main adjuvant chemotherapy regimen was TPF and PF (cisplatin $80 \mathrm{mg} / \mathrm{m}^{2}$ divided into 3 parts on days $1-3$, and fluorouracil $750 \mathrm{mg} / \mathrm{m}^{2}$ per day on days $1-5$, every 3 week).

\section{Follow-up}

The patients were followed up every 3 month during the first 3 years and every 6 months thereafter or until death. Each follow-up consisted of physical examination, basic serum chemistry, flexible fiberoptic endoscopy, MRI of the nasopharynx and neck, chest radiography or CT, abdominal sonography, and a whole-body bone scan. MRI was performed after SIB-IMRT was completed and to detect locoregional or distant relapse.

\section{Statistical analysis}

The endpoints of this study were overall survival (OS; time to death due to any cause), disease-free survival (DFS; time to treatment failure or death from any cause), distant failure-free survival (DMFS; time to distant metastasis), and locoregional recurrence-free survival (LRFS; time to locoregional persistence or recurrence). All the events were estimated from historical diagnosis. OS, DFS, DMFS, and LRRFS were 
calculated using the Kaplan-Meier method [15], and survival curves were estimated using log-rank tests [15]. Statistical Package for the Social Sciences, version 23.0, was used for statistical analysis.

\section{Results}

\section{T category classification}

Of the 89 patients with stage T4 NPC according to the 7th edition, 61 were downgraded to T3 considering the 8 th edition as the cancer had reached to the medial or LP muscles. A total of 82 patients with stage T1 NPC according to the 7th edition were reclassified as stage T2 considering the 8th edition on the basis of prevertebral muscle extension (Table 3 ).

Table 4 presents the 5-year survival rates for different end points of T categories in the 7th and 8th editions. Figure $1 \mathrm{~A}$ and $1 \mathrm{~B}$ show the OS curves for the $\mathrm{T}$ categories in the 7 th and 8 th editions. There were significant differences between T4 and T1, T4 and T2, and T4 and T3 categories in the 7th and 8th editions $(P<0.001$ for T4 and T1, T4 and T2; $P=0.007$ for T4 and T3 in the 7th edition; $P=0.004$ for T4 and T3 in the 8th edition). The OS rates between T3 and T2, and T3 and T1 categories in the 7th edition were not significantly different $(P=0.106$ and $P=0.066$, respectively), whereas these categories in the 8th edition were considerably different $(P=0.008$ and $P=0.004$, respectively). Figure 1C and 1D show the LRRFS rates of T categories in both the staging systems. In the 8th edition, the difference between T2 and T4 was statistically significant, while that in the 7th edition was not $(P=0.07$ and $P=0.011$, respectively). Therefore, the 8th edition had improved the prognosis value of NPC compared with the 7th edition. Figure 1E and 1F show the DFS curves; except for the difference between T1 and T2 categories, the difference between all other combinations of classifications were statistically significant.

\section{$\mathrm{N}$ category classification}

In the 8th edition, the supraclavicular fossa (SCF) was replaced with the lower neck (below the caudal border of the cricoid cartilage), which led to the upstaging of 18 patients from N2 to N3 (Table 3).

Table 4 presents the 5-year survival rates for different end points of $\mathrm{N}$ categories in the 7th and 8th editions. Figure 2 shows the OS, DFS, and DMFS survival curves for each staging system. The OS and DFS in the 7th edition system for N2 and N3a stages were not significantly different $(P=0.472$ and $P=$ 0.954 , respectively, Figure 2A, 2C), whereas the OS and DFS for N2 and N3 using the 8th edition were statistically different $(P=0.046$ and $P=0.043$, respectively, Figure 2B, 2D). Thus, the 8th edition had a superior prognosis value compared with the 7th edition with respect to $\mathrm{N}$ category classification. Additionally, there was no significant difference between classifications N3a and N3b in the 7th edition system ( $P=0.785$ for OS, $P=0.241$ for DFS, and $P=0.910$ for DMFS; Figure 2A, 2C, 2E). The DFS curves for N3a and N3b even overlapped in the 7th edition (Figure 2C). Therefore, merging N3a and N3b stages in the 8th edition was reasonable.

\section{Stage group classification}


Considering the 8th edition, 40 patients with stage IVA disease were downgraded to stage III (Table 3). No deaths were reported for stage I patients. Table 4a presents the 5-year survival rates for different end points of clinical stages in the 7th and 8th editions. Figure 3 shows the OS and DFS survival curves for each staging system. In both the staging systems, significant differences in OS and DFS were observed for clinical stages $(P<0.05)$ except for stages IVA and IVB, and I and II $(P=0.893$ for OS and $P=0.711$ for DFS; $P=0.549)$.

\section{Discussion}

Based on our study findings, our data show that the 8th edition has a superior prognostic value for patients with NPC than the 7th edition.

In the treatment of NPC, IMRT has become the optimal radiation technique because of its clear advantage in target dose uniformity and better protection of adjacent organs at risk compared with 2dimensional radiotherapy (2D-RT) or 3-dimensional conformal radiotherapy (3D-CRT). It can be administered in 2 ways, sequential technology (SEQ-IMRT) [16, 17] or SIB-IMRT [18]. Compared with SEQIMRT, SIB-IMRT simply uses a single radiation plan in the entire course of treatment, allowing the simultaneous delivery of different dose levels to different target volumes that reduces the treatment duration and enhances biologically equivalent dose (BED) $[12,19]$.

The TNM staging system is crucial for predicting prognosis, guiding treatment decisions for different risk groups, assessing treatment efficacy, and evaluating clinical outcomes between different centres. Therefore, the TNM staging system should be updated based on the development of radiation technology. The 7th staging system was based on the information data form the 2D-RT era, and several trials have been conducted to determine its value considering the advent of IMRT [20-22]. Zong [20] et al analysed the data of 1241 NPC patients treated with IMRT and revealed that the differences in local relapse-free survival (LRRFS) between $\mathrm{T} 1$ and $\mathrm{T} 2$, and between $\mathrm{T} 2$ and $\mathrm{T} 3$ were not significantly different ( $P=0.055$ and 0.605 , respectively). Additionally, they reported that the hazard ratios for OS and diseasespecific survival between T1 and T2 were not statistically significant. The study considered that the TNM staging system should downgrade stage T2 patients to T1 patients. In a study performed by Chen et al [21] on 181 NPC patients with NO stage, the authors reported that the difference in OS, LRFS, and PFS between $\mathrm{T} 1$ and $\mathrm{T} 2$, and between $\mathrm{T} 3$ and $\mathrm{T} 4$ was not statistically significant. In this study, we also confirmed that there were no differences in OS, DFS, and DMFS between T1 and T2 $(P=0.987,0.984$, and 0.191). Fortunately, the 8th staging system was revised after the introduction of IMRT as a treatment option and several previous studies [11,23-25] have reported its superiority over the 7th edition staging system. Our data confirmed that the 8 th edition had better prognostic performance than the $7^{\text {th }}$ edition.

For T categories, our data found that the T-classification in the 8th edition showed better separation between T3 and T2, and T3 and T1 compared to OS and LRRFS, while there were no significant differences in the T-classification in the $7^{\text {th }}$ edition. A retrospective study performed by Pan et al [11] on 1609 patients staged based on MRI findings and treated with IMRT at 2 major centres in Hong Kong and 
Mainland China (median follow-up of 5 years) found that there were statistically significant differences among OS between T3 and T2 $(P=0.009)$. Additionally, OuYang et al [24] retrospectively studied 899 patients with NPC (from Hong Kong, Guangzhou, and Guangxi) who were staged based on MRI findings and received IMRT; this study compared the 7th and 8th staging systems and reported that the 8th edition had better differentiation of OS between T3 and T2 $(P=0.003)$. All these data confirmed that it was reasonable to downstage MP and LP from T4 in the 7th edition to T2 in the 8th edition. This change has increased the survival difference values between $\mathrm{T} 3$ and $\mathrm{T} 2$, and also resulted in improved classification of patients with NPC.

In terms of N categories, replacing SCF with the lower neck region to differentiate N1-2 and N3 is the main revision in the 8th edition. $\mathrm{Ng}$ et al [10] first explored the possibility of replacing the SCF by levels IV and $\mathrm{Vb}$ as a demarcating criterion for the N3 category, and found this method potentially useful. A few studies debated that the definition of SCF involvement is primarily based on clinical examination and defining SCF using clinical landmarks is difficult [6-8]. However, the lower neck, as an anatomical landmark, can be reliably defined on the basis of both physical examination and cross-sectional images, thereby making it more convenient in clinical practice.

Several studies [23-25] have reported that the new staging system is useful in predicting outcomes with regard to N categories. In a study performed by Tang [23] that included 1790 NPC patients, the survival curves between different groups were accurately differentiated considering the 8th staging system. Another respective study also confirmed that the T-classification according to the 8th staging system showed better differentiation compared with that performed using the 7th edition [25]. Similarly, our results showed a clear difference between N2 and N3 among OS and DFS according to the new staging system. Moreover, we found no differences between N3a and N3b among OS, DFS, and DMFS considering the 7th staging system, indicating that this subgroup was unnecessary.

In terms of clinical stage, the 8th edition has upgraded IVC to IVB, and merged IVA and IVB from the 7th edition into IVA. Our data showed that the segregation of IVA and IVB in terms of survival was inaccurate in the 7th staging system as IVA and IVB share similar 5-year OS and DFS rates.

Our study included patients with NPC from a centre between year 2009 and 2013 with a relative long follow-up time. However, because of the radiation technique, only 300 patients in our study underwent SIB-IMRT. This small number of patients may result in low end-point events that may weaken the power to convince the differences between both the staging systems. Another limitation was the nature of the study (retrospective), and hence, prospective multicenter studies are required to be performed to confirm the results of our study.

\section{Conclusion}

The 8th edition of the UICC/AJCC staging system has a higher prognostic value and better classification compared with the 7th edition considering SIB-IMRT as the latest treatment option. The comparison 
results of both the staging systems should be further confirmed in multicenter, prospective trials with large sample sizes.

\section{Declarations}

\section{Ethics approval and consent to participate}

The work described has been carried out in accordance with The Code of Ethics of the World Medical Association (Declaration of Helsinki) for experiments involving humans. The project was approved by the West China hospital ethics committee. All the partecipants signed an informed consent to partecipate in this study and a consent for the publication of the anonymized data has also been obtained.

\section{Consent for publication}

Not applicable.

\section{Availability of data and materials}

The datasets analysed during the current study are available from the corresponding author on reasonable request.

\section{Competing interests}

Not applicable.

\section{Funding}

Not applicable.

\section{Authors' contributions}

Tao He, Ruo-Nan Yan and Hua-Ying Chen contributed equally to this work.

T.H., R.N.Y. and H.Y.C. led the study. T.H. performed the data analysis and implemented the methodology; T.H., R.N.Y., H.Y.C., Y.Y.Z., Z.Z.X., collected the data; R.N.Y. prepared the original draft; F.L, B.F.S, J.C.M. and X.R.W. helped to perfect the Figs. L.L. reviewed and edited the final manuscript. All authors revised the manuscript for important intellectual content, and approved the final version of the manuscript. All authors agreed to be accountable for all aspects of the work in ensuring that questions related to the accuracy or integrity of any part of the work are appropriately investigated and resolved.

\section{Corresponding author}

Correspondence to: Lei Liu.

\section{Acknowledgement}


We would like to thank sagesci Co., Itd (www.sagesci.cn) for English language editing.

\section{Author information}

Affiliatiions

Department of Radiation Oncology, Cancer Center, West China Hospital, Sichuan University, Chengdu, Sichuan, PR China

The sixth floor of the third inpatient building of West China Hospital of Sichuan University, Wuhou District, Chengdu City, Sichuan Province, China.

Tao He, Ruo-Nan Yan, Yuan-Yuan Zeng, Zhong-Zheng Xiang, Fang Liu, Bian-Fei Shao, Jia-Chun Ma, XiRan Wang, Lei Liu*

Department of Radiation Oncology, Cancer Center, West China Hospital, Sichuan University, Chengdu, Sichuan, PR China

Hua-Ying Chen

\section{References}

1. Liao XB, Mao YP, Liu LZ, Tang LL, Sun Y, Wang $Y$ et al. How does magnetic resonance imaging influence staging according to AJCC staging system for nasopharyngeal carcinoma compared with computed tomography? Int J Radiat Oncol Biol Phys. 2008; 72:1368-77.

2. Dubrulle F, Souillard R, Hermans R. Extension patterns of nasopharyngeal carcinoma. Eur Radiol. 2007; 17:2622-30.

3. Zhang GY, Huang Y, Cai XY, Chen XP, Xu T, Wu J et al. Prognostic value of grading masticator space involvement in nasopharyngeal carcinoma according to MR imaging findings. Radiology. 2014; 273:136-43.

4. Toledano I, Graff P, Serre A, Boisselier P, Bensadoun RJ, Ortholan C et al. Intensity-modulated radiotherapy in head and neck cancer: results of the prospective study GORTEC 2004-03. Radiother Oncol. 2012; 103:57-62.

5. Su SF, Han F, Zhao C, Chen CY, Xiao WW, Li JX et al. Long-term outcomes of early-stage nasopharyngeal carcinoma patients treated with intensity-modulated radiotherapy alone. Int J Radiat Oncol Biol Phys. 2012; 82:327-33.

6. Zhang B, Mo Z, Du W, Wang Y, Liu L, Wei Y. Intensity-modulated radiation therapy versus 2D-RT or 3DCRT for the treatment of nasopharyngeal carcinoma: A systematic review and meta-analysis. Oral Oncol. 2015; 51:1041-46.

7. Wolden SL, Chen WC, Pfister DG, Kraus DH, Berry SL, Zelefsky MJ. Intensity-modulated radiation therapy (IMRT) for nasopharynx cancer: update of the Memorial Sloan-Kettering experience. Int $J$ 
Radiat Oncol Biol Phys. 2006; 64:57-62.

8. Peng G, Wang T, Yang KY, Zhang S, Zhang T, Li Q et al. A prospective, randomized study comparing outcomes and toxicities of intensity-modulated radiotherapy vs. conventional two-dimensional radiotherapy for the treatment of nasopharyngeal carcinoma. Radiother Oncol. 2012; 104:286-93.

9. Yue D, Xu YF, Zhang F, Lin L, Mao YP, Li WF et al. Is replacement of the supraclavicular fossa with the lower level classification based on magnetic resonance imaging beneficial in nasopharyngeal carcinoma? Radiother Oncol. 2014; 113:108-14.

10. Ng WT, Lee AW, Kan WK, Chan J, Pang ES, Yau TK et al. N-staging by magnetic resonance imaging for patients with nasopharyngeal carcinoma: pattern of nodal involvement by radiological levels. Radiother Oncol. 2007; 82:70-5.

11. Pan JJ, Ng WT, Zong JF, Chan LL, O'Sullivan B, Lin SJ et al. Proposal for the 8th edition of the AJCC/UICC staging system for nasopharyngeal cancer in the era of intensity-modulated radiotherapy. Cancer. 2016; 122:546-58.

12. Chen SW, Yang SN, Liang JA, Shiau AC, Lin FJ. Comparative dosimetric study of two strategies of intensity-modulated radiotherapy in nasopharyngeal cancer. Med Dosim. 2005; 30:219-27.

13. Lin YH, Huang TL, Chien CY, Chen HC, Hsu HC, Huang EY et al. Pretreatment prognostic factors of survival and late toxicities for patients with nasopharyngeal carcinoma treated by simultaneous integrated boost intensity-modulated radiotherapy. Radiat Oncol. 2018; 13:45.

14. Lin S, Pan J, Han L, Zhang X, Liao X, Lu JJ. Nasopharyngeal carcinoma treated with reduced-volume intensity-modulated radiation therapy: report on the 3-year outcome of a prospective series. Int J Radiat Oncol Biol Phys. 2009; 75:1071-8.

15. Kaplan E, Meier P. Nonparametric estimation from incomplete 558 observations. J Am Stat Assoc. 1958; 53:457-81.

16. Lertbutsayanukul C, Khorprasert C, Shotelersuk K, Jumpangern C, Sanghangthum T, Oonsiri S et al. Intensity-modulated radiation therapy in head-and-neck cancer, first report in Thailand. J Med Assoc Thai. 2006; 89:2068-76.

17. Songthong A, Chakkabat C, Kannarunimit D, Lertbutsayanukul C. Efficacy of intensity-modulated radiotherapy with concurrent carboplatin in nasopharyngeal carcinoma. Radiology and oncology. 2015; 49:155-62.

18. Butler EB, Teh BS, Grant WH, 3rd, Uhl BM, Kuppersmith RB, Chiu JK et al. Smart (simultaneous modulated accelerated radiation therapy) boost: a new accelerated fractionation schedule for the treatment of head and neck cancer with intensity modulated radiotherapy. Int J Radiat Oncol Biol Phys. 1999; 45:21-32.

19. Dogan N, King S, Emami B, Mohideen N, Mirkovic N, Leybovich LB et al. Assessment of different IMRT boost delivery methods on target coverage and normal-tissue sparing. Int J Radiat Oncol Biol Phys. 2003; 57:1480-91.

20. Zong J, Lin S, Lin J, Tang L, Chen B, Zhang M et al. Impact of intensity-modulated radiotherapy on nasopharyngeal carcinoma: Validation of the 7th edition AJCC staging system. Oral Oncol. 2015; 
51:254-9.

21. Chen YP, Tang LL, Zhang WN, Mao YP, Chen L, Sun Y et al. Prognostic Value and Grading of MRIBased T Category in Patients With Nasopharyngeal Carcinoma Without Lymph Node Metastasis Undergoing Intensity-Modulated Radiation Therapy. Medicine (Baltimore). 2015; 94:e1624.

22. Han L, Lin SJ, Pan JJ, Chen CB, Zhang Y, Zhang XC et al. Prognostic factors of 305 nasopharyngeal carcinoma patients treated with intensity-modulated radiotherapy. Chin J Cancer. 2010; 29:145-50.

23. Tang LL, Chen YP, Mao YP, Wang ZX, Guo R, Chen L et al. Validation of the 8th Edition of the UICC/AJCC Staging System for Nasopharyngeal Carcinoma From Endemic Areas in the IntensityModulated Radiotherapy Era. J Natl Compr Canc Netw. 2017; 15:913-19.

24. OuYang PY, Xiao Y, You KY, Zhang LN, Lan XW, Zhang XM et al. Validation and comparison of the 7th and 8th edition of AJCC staging systems for non-metastatic nasopharyngeal carcinoma, and proposed staging systems from Hong Kong, Guangzhou, and Guangxi. Oral Oncol. 2017; 72:65-72.

25. Yang XL, Wang Y, Liang SB, He SS, Chen DM, Chen HY et al. Comparison of the seventh and eighth editions of the UICC/AJCC staging system for nasopharyngeal carcinoma: analysis of 1317 patients treated with intensity-modulated radiotherapy at two centers. BMC Cancer. 2018; 18:606.

\section{Tables}

Table 1. Criteria of the 7th and 8th editions of the UICC/AJCC staging system for nasopharyngeal carcinoma. ( before the third paragraph of the Introduction section falls behind and the fourth paragraph falls.) 


\begin{tabular}{|c|c|c|}
\hline & 7th edition & 8th edition \\
\hline \multicolumn{3}{|l|}{$\begin{array}{l}\mathrm{T} \\
\text { category }\end{array}$} \\
\hline & $\begin{array}{l}\text { T1: Nasopharynx, oropharynx, or } \\
\text { nasal cavity without } \\
\text { parapharyngeal extension }\end{array}$ & $\begin{array}{l}\text { T1: Nasopharynx, oropharynx, or nasal cavity without } \\
\text { parapharyngeal extension }\end{array}$ \\
\hline & T2: Parapharyngeal extension & $\begin{array}{l}\text { T2: Parapharyngeal extension, adjacent soft tissue } \\
\text { involvement (medial pterygoid, lateral pterygoid, } \\
\text { prevertebral muscles) }\end{array}$ \\
\hline & $\begin{array}{l}\text { T3: Bony structures of skull base } \\
\text { and/or paranasal sinuses }\end{array}$ & $\begin{array}{l}\text { T3: Bony structures (skull base, cervical vertebra) } \\
\text { and/or paranasal sinuses }\end{array}$ \\
\hline & $\begin{array}{l}\text { T4: Intracranial, cranial nerves, } \\
\text { hypopharynx, orbit, } \\
\text { infratemporal fossa/masticator } \\
\text { space }\end{array}$ & $\begin{array}{l}\text { T4: Intracranial extension, cranial nerve, } \\
\text { hypopharynx, orbit, extensive soft tissue involvement } \\
\text { (beyond the lateral surface of the lateral pterygoid } \\
\text { muscle, parotid gland) }\end{array}$ \\
\hline \multicolumn{3}{|l|}{$\begin{array}{l}\mathrm{N} \\
\text { category }\end{array}$} \\
\hline & $\begin{array}{l}\text { N0: No regional lymph node } \\
\text { metastasis }\end{array}$ & NO: No regional lymph node metastasis \\
\hline & \multirow{2}{*}{$\begin{array}{l}\text { N1: Unilateral cervical, unilateral } \\
\text { or bilateral retropharyngeal } \\
\text { lymph nodes above Above the } \\
\text { supraclavicular }\end{array}$} & N1: Retropharyngeal (regardless of laterality) \\
\hline & & $\begin{array}{l}\text { Cervical: unilateral, } \leq 6 \mathrm{~cm} \text {, and above caudal border } \\
\text { of cricoid cartilage }\end{array}$ \\
\hline & $\begin{array}{l}\text { N2: Bilateral metastasis in } \\
\text { lymph nodes, } \leq 6 \mathrm{~cm} \text { in greatest } \\
\text { dimension, above the } \\
\text { supraclavicular fossa }\end{array}$ & $\begin{array}{l}\text { N2: Cervical: bilateral, } \leq 6 \mathrm{~cm} \text {, and above caudal } \\
\text { border of cricoid cartilage }\end{array}$ \\
\hline & 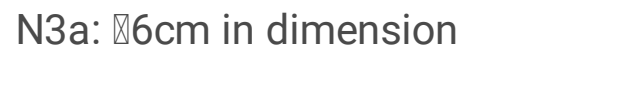 & $\begin{array}{l}\text { N3: } ₫ 6 \mathrm{~cm} \text { and/or below caudal border of cricoid } \\
\text { cartilage (regardless of laterality) }\end{array}$ \\
\hline & \multicolumn{2}{|l|}{ N3b: Supraclavicular fossa } \\
\hline \multicolumn{3}{|l|}{$\begin{array}{l}\text { Clinical } \\
\text { stage }\end{array}$} \\
\hline & I: T1N0M0 & I: T1N0M0 \\
\hline & II: T2N0-1M0, T1NIM0 & II: T2N0-1M0, T1NIM0 \\
\hline & III: T1-2N2M0, T3NO-2M0 & III: T3N0-2M0, T1-2N2M0 \\
\hline & IVA: T4N0-2M0 & IVA: T4 or N3M0 \\
\hline & IVB: Any T1-4N3M0 & IVB: Any T, any N M1 \\
\hline
\end{tabular}

Abbreviations: UICC/AJCC, Union for International Cancer Control/American Joint Committee on Cancer. 
Table 2. Patient characteristics

\begin{tabular}{|c|c|}
\hline Characteristic & 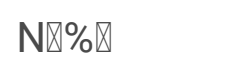 \\
\hline \multicolumn{2}{|l|}{ Sex } \\
\hline Male & $215 \rrbracket 71.7 \% \bigotimes$ \\
\hline Female & $85 \llbracket 28.3 \% \rrbracket$ \\
\hline \multicolumn{2}{|l|}{ Age (y) } \\
\hline$<45$ & $126 \rrbracket 42 \% \rrbracket$ \\
\hline $45-60$ & $131 \otimes 43.7 \% \bigotimes$ \\
\hline$\geq 60$ & $43 \rrbracket 14.3 \% \rrbracket$ \\
\hline \multicolumn{2}{|l|}{ CT } \\
\hline IC & $173 \rrbracket 57.6 \% \bigotimes$ \\
\hline $\mathrm{CC}$ & $67 \rrbracket 22.3 \% \rrbracket$ \\
\hline $\mathrm{CA}$ & $42 \bigotimes 14 \% \rrbracket$ \\
\hline NO CT & $18 \llbracket 6 \% \bigotimes$ \\
\hline
\end{tabular}

Abbreviations: CT, chemotherapy. IC, induction+ concurrent chemotherapy. CC囚concurrent chemotherapy. CA, concurrent + adjuvant chemotherapy.

Table 3. The Distribution of both two staging system 


\begin{tabular}{|c|c|c|c|c|c|c|c|c|c|c|}
\hline \multicolumn{11}{|c|}{ 7th edition } \\
\hline & os & DFS & LRRFS & & OS & DFS & DMFS & & os & DFS \\
\hline $\begin{array}{l}\mathrm{T} \\
\text { category }\end{array}$ & & & & $\begin{array}{l}\mathrm{N} \\
\text { category }\end{array}$ & & & & $\begin{array}{l}\text { Clinical } \\
\text { stage }\end{array}$ & & \\
\hline T1 & 82 & 82 & 82 & No & 50 & 50 & 50 & I & 18 & 18 \\
\hline $\mathrm{T} 2$ & 62 & 62 & 62 & N1 & 82 & 82 & 82 & II & 50 & 50 \\
\hline T3 & 67 & 67 & 67 & N2 & 141 & 141 & 141 & III & 126 & 126 \\
\hline \multirow[t]{4}{*}{ T4 } & 89 & 89 & 89 & N3a & 8 & 8 & 8 & IVA & 79 & 79 \\
\hline & & & & N3b & 19 & 19 & 19 & IVB & 27 & 27 \\
\hline & 8th $\epsilon$ & ition & & & & & & & & \\
\hline & OS & DFS & LRRFS & & OS & DFS & DMFS & & os & DFS \\
\hline $\begin{array}{l}\mathrm{T} \\
\text { category }\end{array}$ & & & & $\begin{array}{l}\mathrm{N} \\
\text { category }\end{array}$ & & & & $\begin{array}{l}\text { Clinical } \\
\text { stage }\end{array}$ & & \\
\hline $\mathrm{T} 1$ & 80 & 80 & 80 & No & 50 & 50 & 50 & I & 18 & 18 \\
\hline T2 & 64 & 64 & 64 & N1 & 82 & 82 & 82 & II & 50 & 50 \\
\hline T3 & 128 & 128 & 128 & N2 & 123 & 123 & 123 & III & 166 & 166 \\
\hline T4 & 28 & 28 & 28 & N3 & 45 & 45 & 45 & IVA & 66 & 66 \\
\hline
\end{tabular}

Table 4. Survival rates at 5-year 


\begin{tabular}{|llllllll|}
\hline 7th edition & & & & \multicolumn{5}{ll}{ 8th edition } \\
\hline T category & OS & DFS & LRRFS & T category & OS & DFS & LRRFS \\
\hline T1 & $95.1 \%$ & $91.5 \%$ & $98.8 \%$ & T1 & $95 \%$ & $91.3 \%$ & $98.7 \%$ \\
\hline T2 & $93.5 \%$ & $90.1 \%$ & $95.1 \%$ & T2 & $93.7 \%$ & $88.8 \%$ & $95.2 \%$ \\
\hline T3 & $84.6 \%$ & $76.6 \%$ & $89.6 \%$ & T3 & $81.4 \%$ & $72.6 \%$ & $91.4 \%$ \\
\hline T4 & $69.5 \%$ & $58.2 \%$ & $83.3 \%$ & T4 & $56.5 \%$ & $50 \%$ & $78.5 \%$ \\
\hline N category & OS & DFS & DMFS & N category & OS & DFS & DMFS \\
\hline N0 & $97 \%$ & $97 \%$ & $98 \%$ & N0 & $97 \%$ & $97 \%$ & $98 \%$ \\
\hline N1 & $84.4 \%$ & $75.3 \%$ & $92.3 \%$ & N1 & $87.8 \%$ & $75.3 \%$ & $92.3 \%$ \\
\hline N2 & $84.4 \%$ & $75.8 \%$ & $88.4 \%$ & N2 & $84.8 \%$ & $77.1 \%$ & $89 \%$ \\
\hline N3a & $75 \%$ & $75 \%$ & $75 \%$ & N3 & $72.3 \%$ & $61.5 \%$ & $78.5 \%$ \\
\hline N3b & $71.1 \%$ & $50.5 \%$ & $74.8 \%$ & & & & \\
\hline Clinical stage & OS & DFS & & Clinical stage & OS & DFS & \\
\hline I & $100 \%$ & $100 \%$ & & I & $100 \%$ & $100 \%$ & \\
\hline II & $98 \%$ & $98 \%$ & & II & $98 \%$ & $98 \%$ & \\
\hline III & $91.3 \%$ & $88.7 \%$ & & III & $88 \%$ & $78.9 \%$ & \\
\hline IVA & $74.6 \%$ & $70.2 \%$ & & IVA & $73.4 \%$ & $61.5 \%$ & \\
\hline IVB & $74.6 \%$ & $72.2 \%$ & & & & & \\
\hline
\end{tabular}

Abbreviations: OS, overall survival. DFS, disease-free survival. LRRFS, locoregional recurrence-free survival. DMFS, distant metastasis-free survival.

Figures 
A
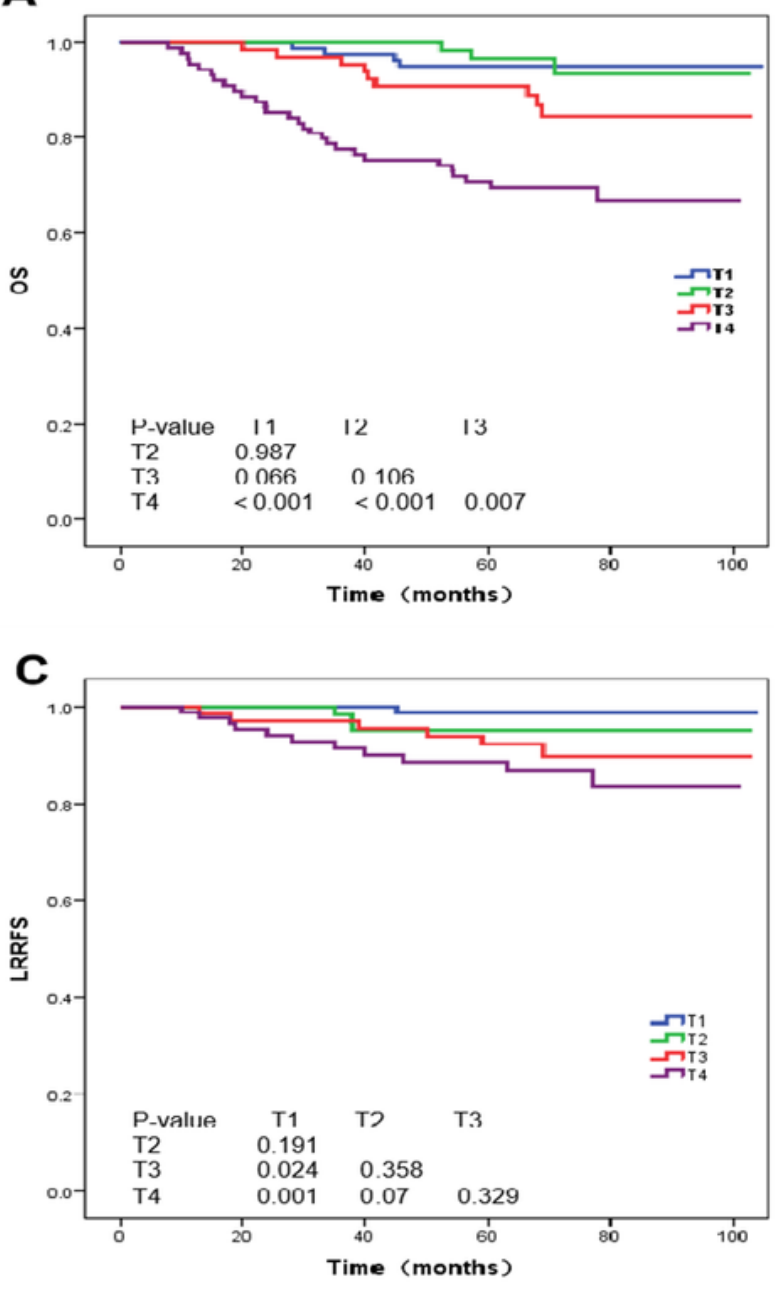

E

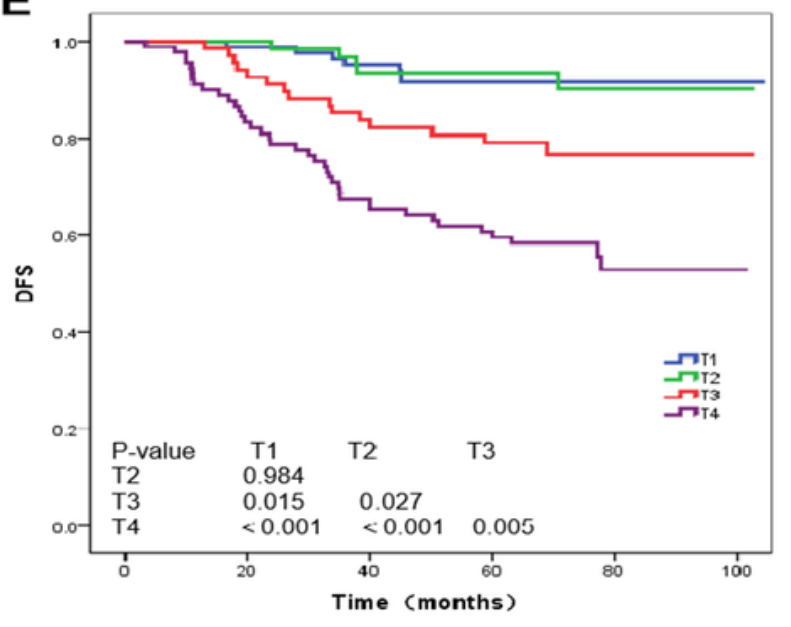

B

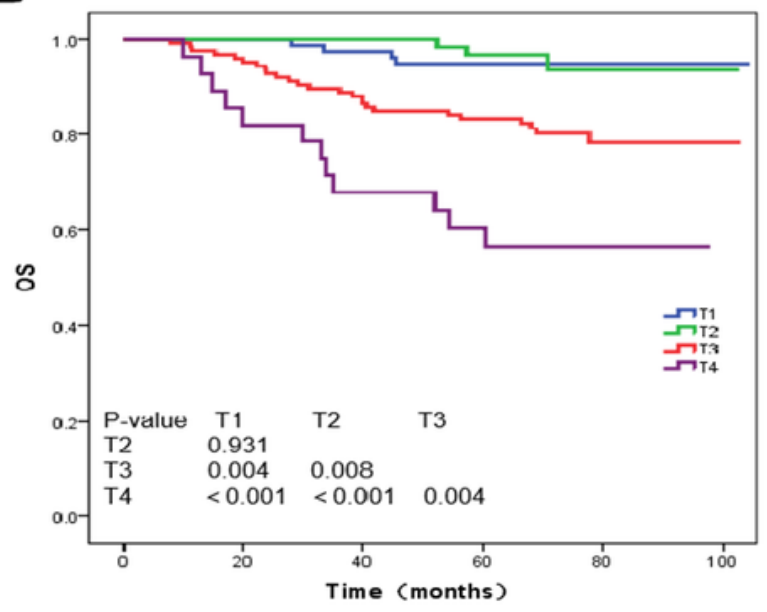

D

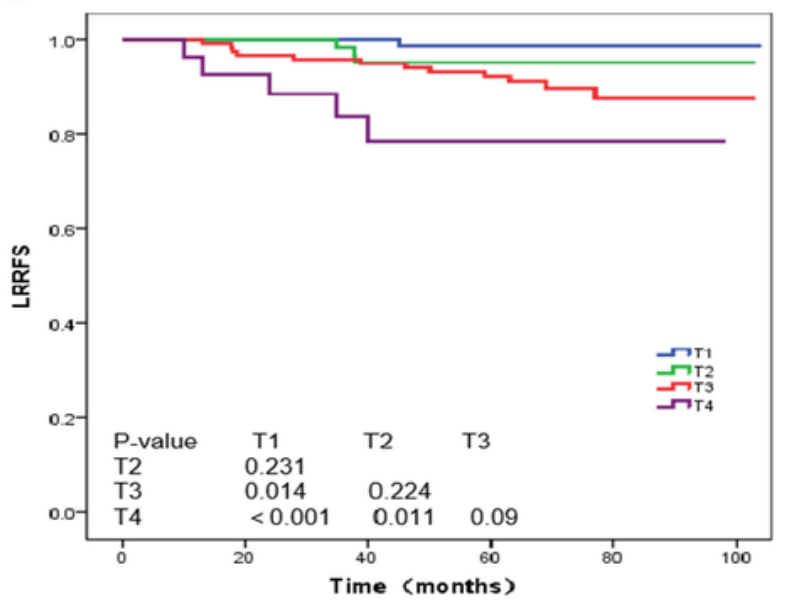

$\mathbf{F}$

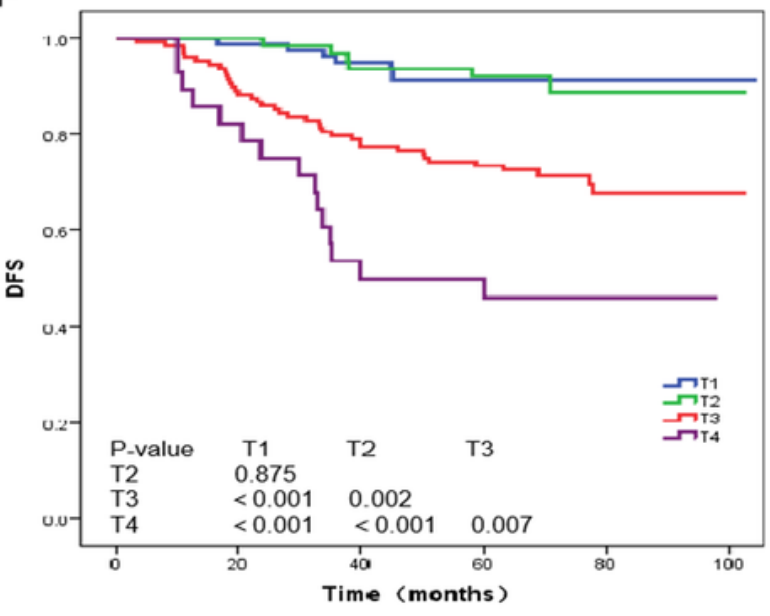

\section{Figure 1}

Overall survival $(A, B)$, locoregional recurrence-free survival $(C, D)$, and disease-free survival $(E, F)$ for each T categories in the 7th $(A, C, E)$ and 8th editions $(B, D, F)$ 
A
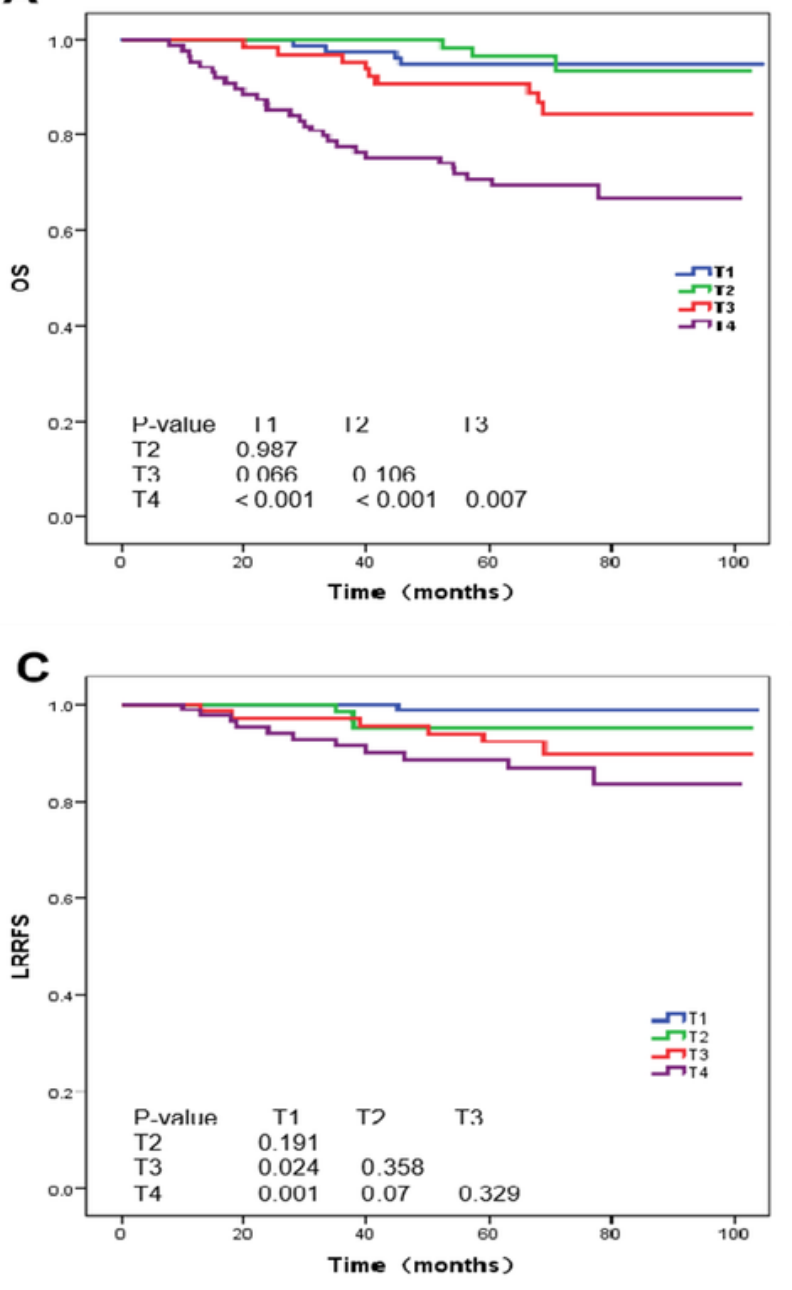

E

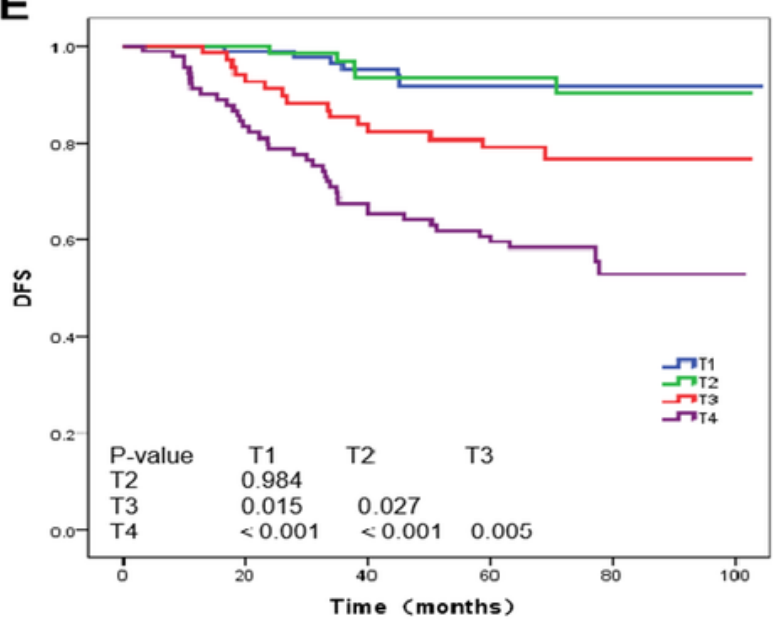

B

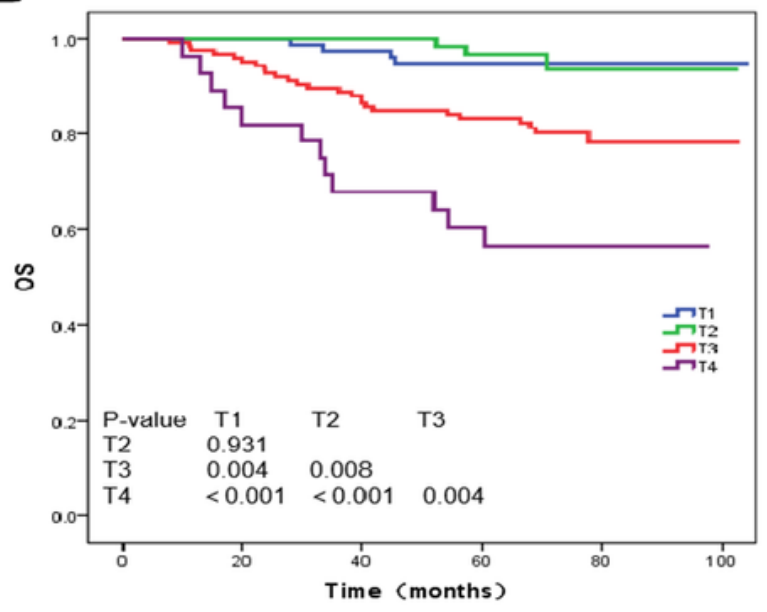

D

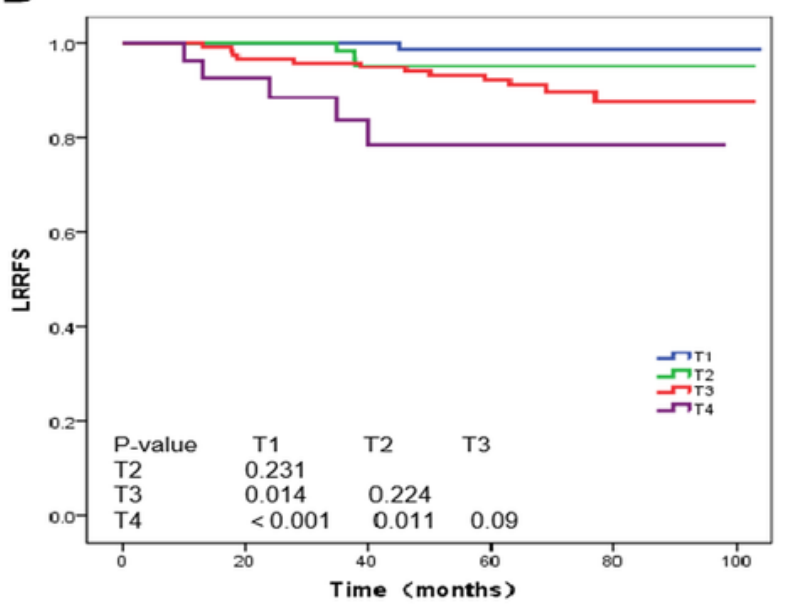

F

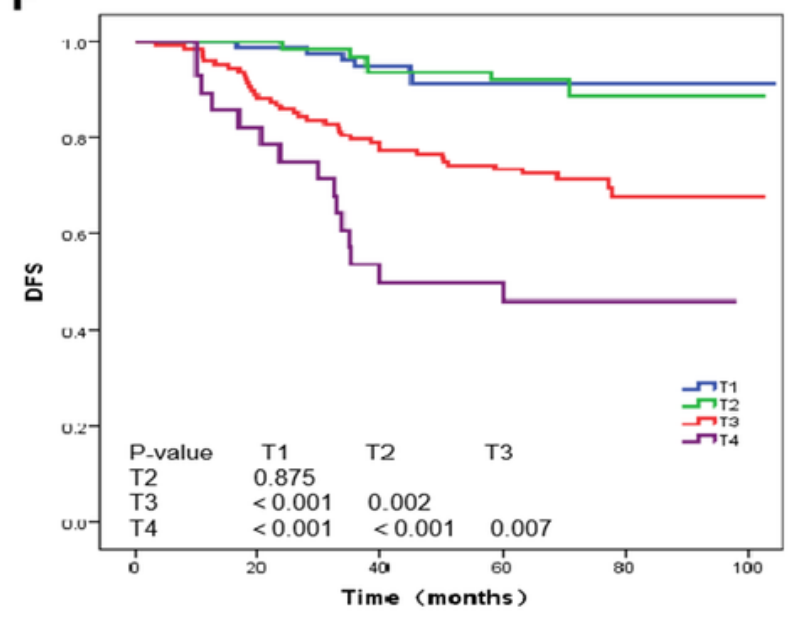

\section{Figure 1}

Overall survival $(A, B)$, locoregional recurrence-free survival $(C, D)$, and disease-free survival $(E, F)$ for each T categories in the 7th $(A, C, E)$ and 8th editions $(B, D, F)$ 
A

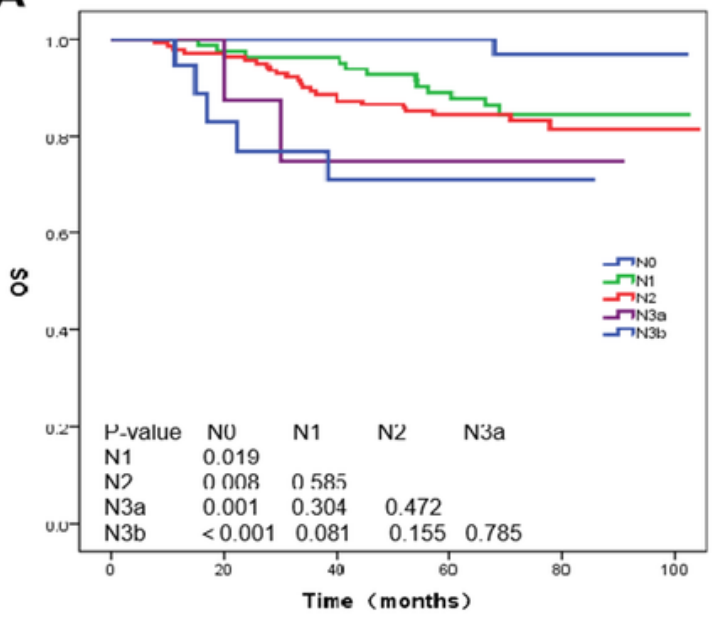

C

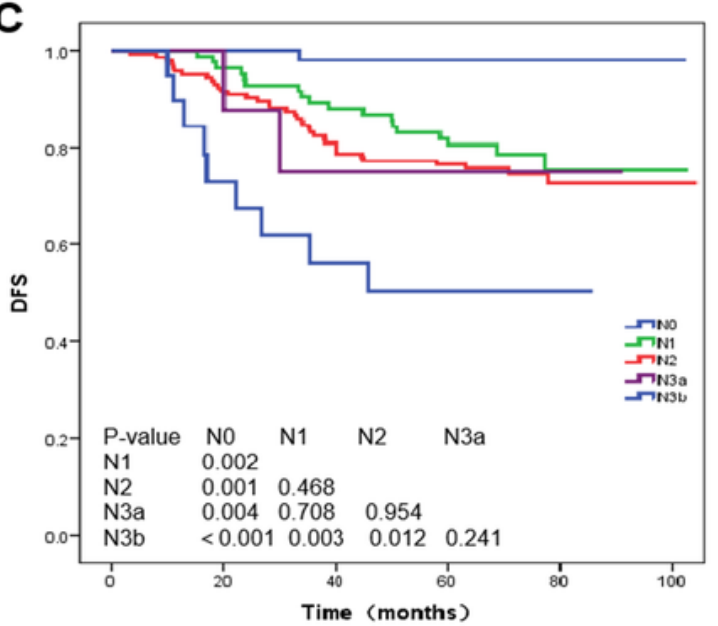

E

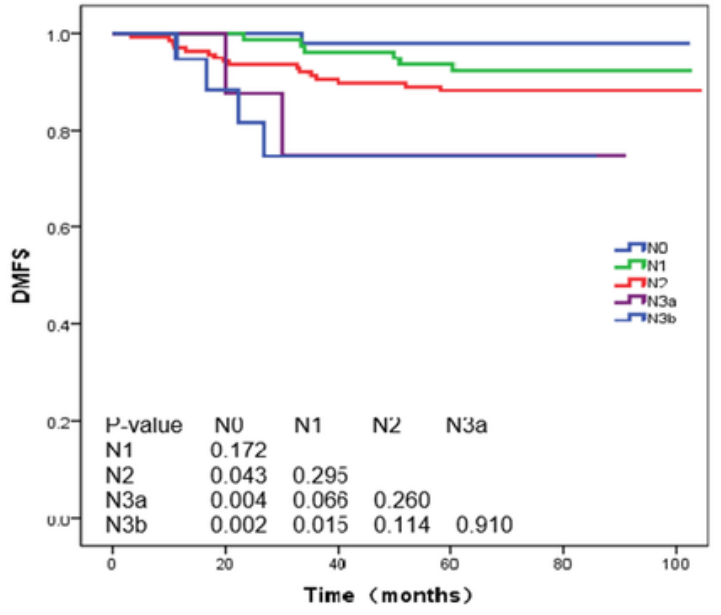

B

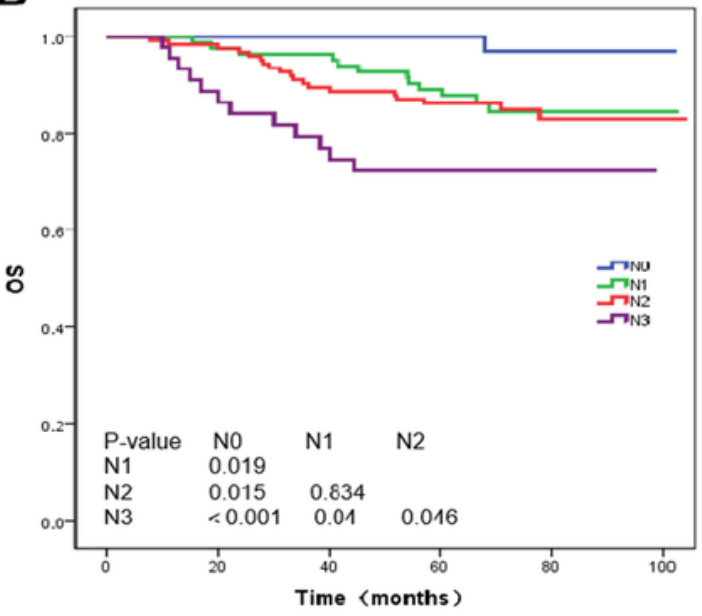

D

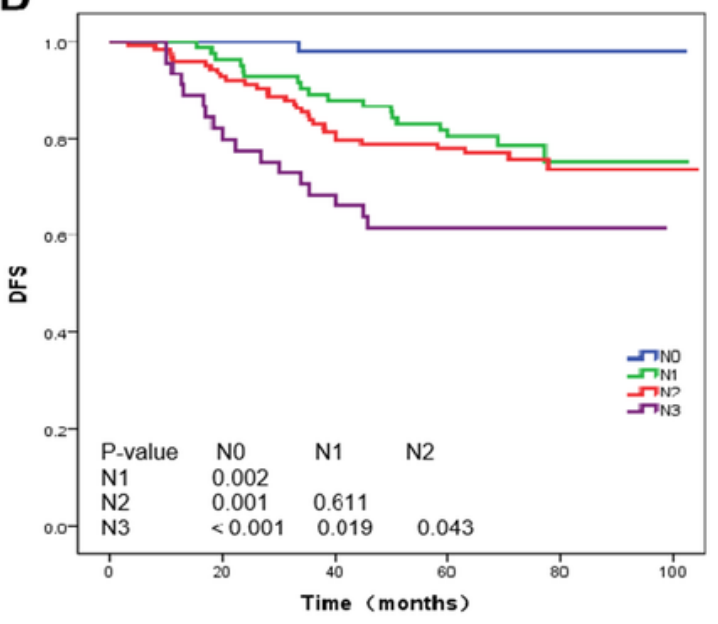

F

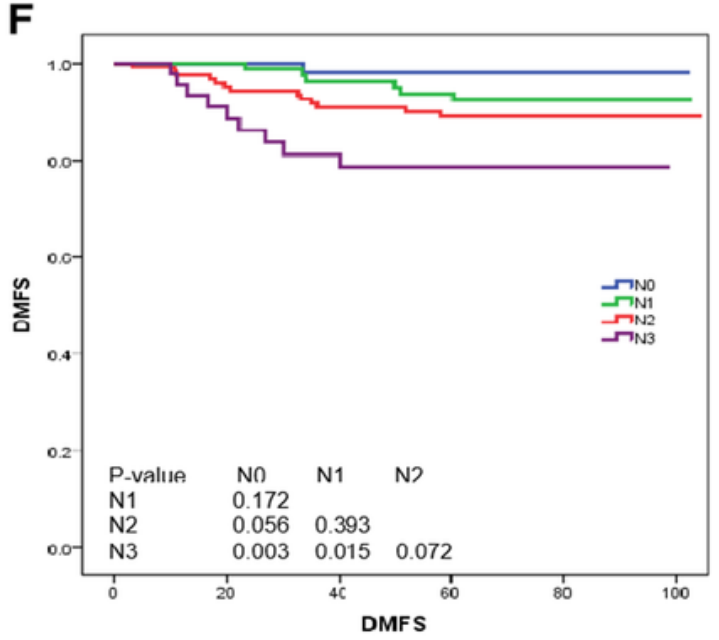

Figure 2

Overall survival $(A, B)$, disease-free survival $(C, D)$, and distant failure-free survival $(E, F)$ for each $N$ categories in the 7th $(A, C, E)$ and 8th editions $(B, D, F)$. 
A

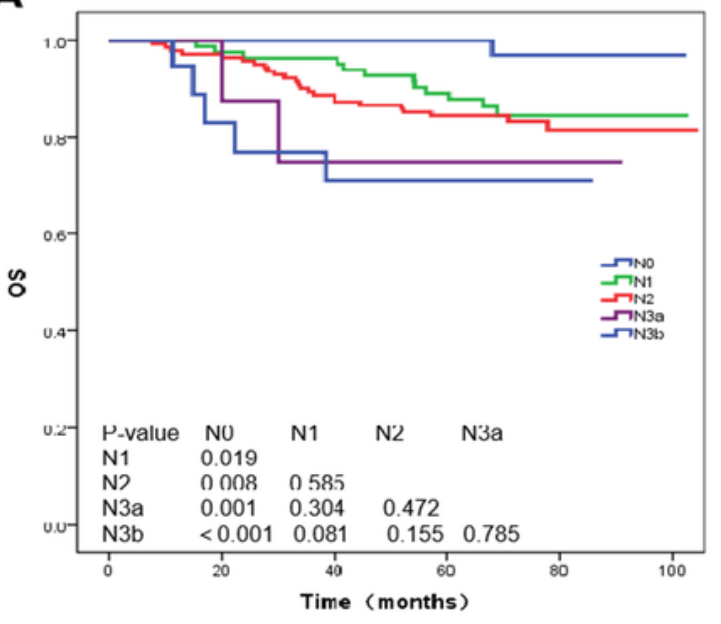

C

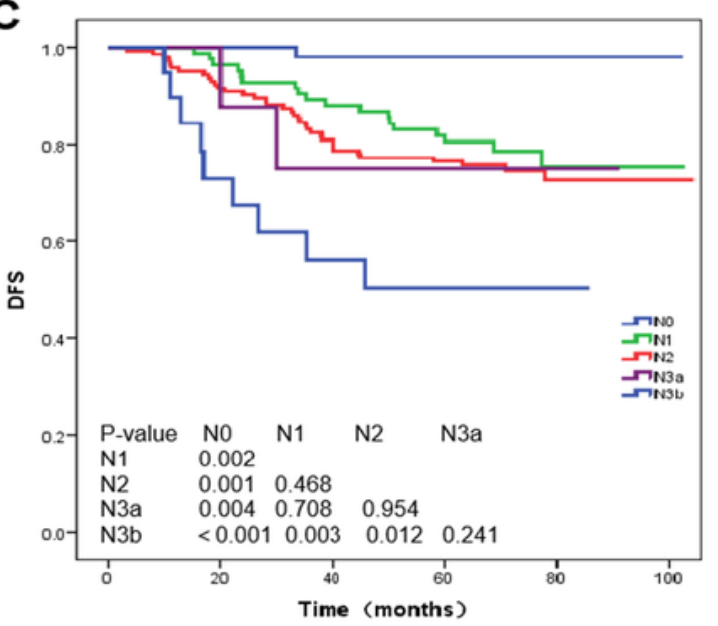

$\mathbf{E}$

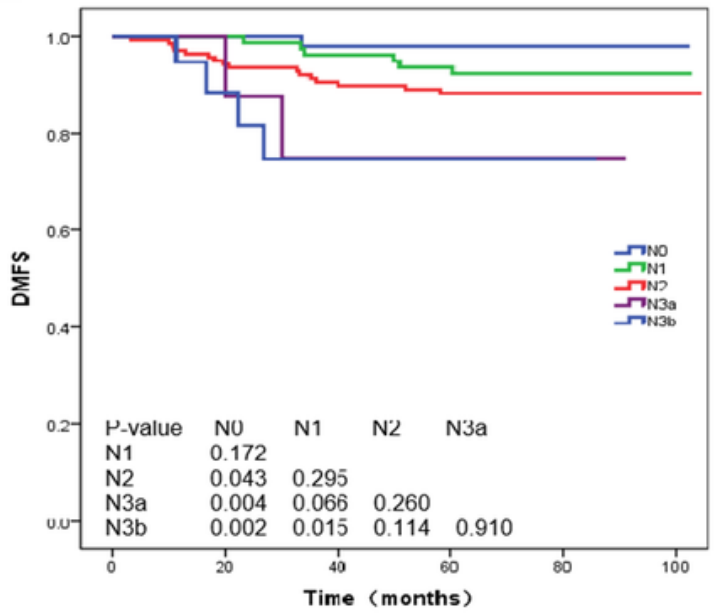

B

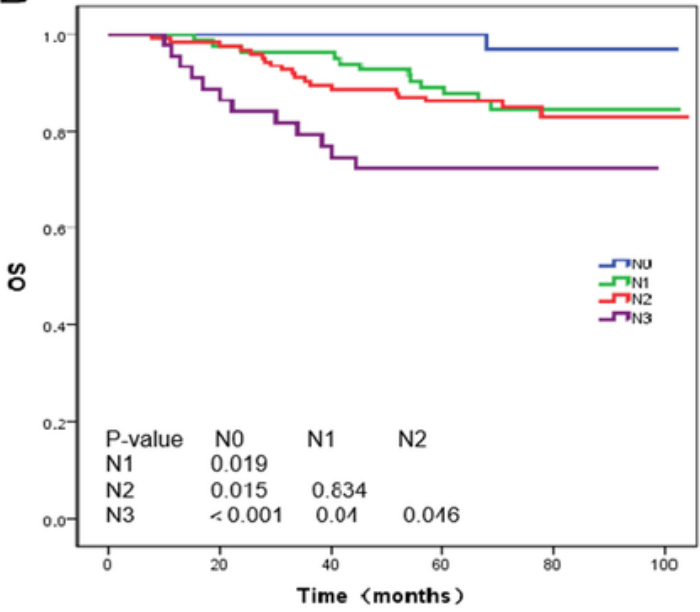

D

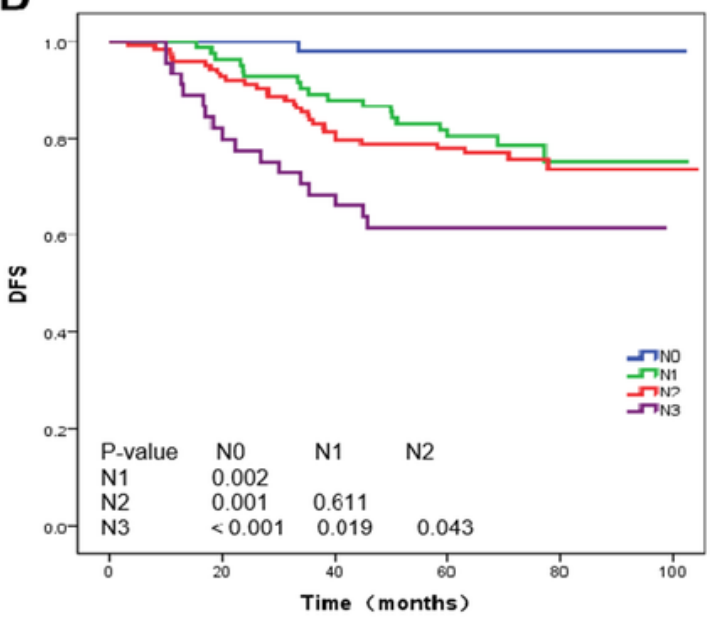

$\mathbf{F}$

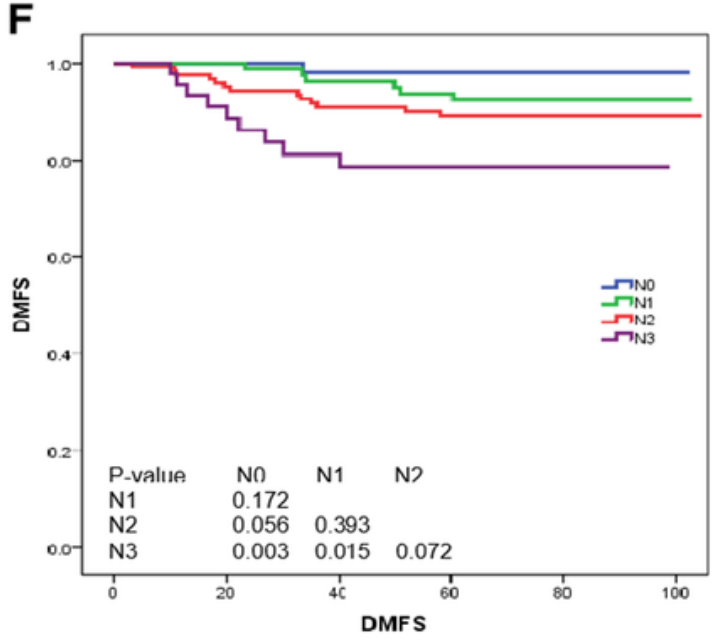

\section{Figure 2}

Overall survival (A, B), disease-free survival (C, D), and distant failure-free survival $(E, F)$ for each $N$ categories in the 7th $(A, C, E)$ and 8th editions $(B, D, F)$. 
A

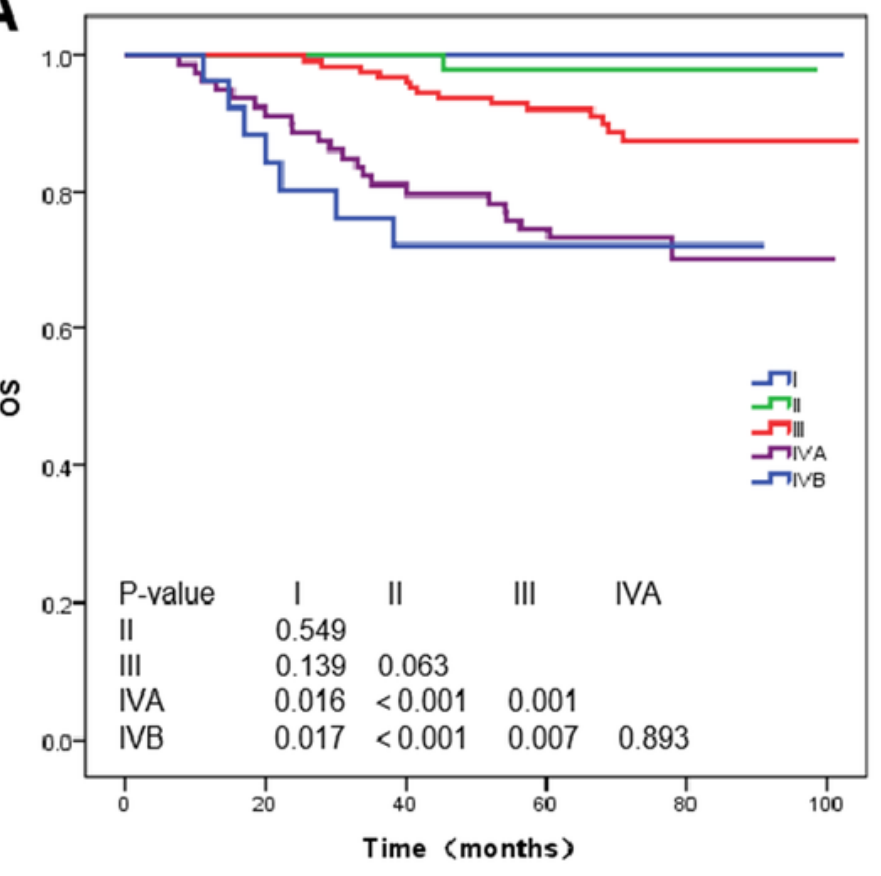

C

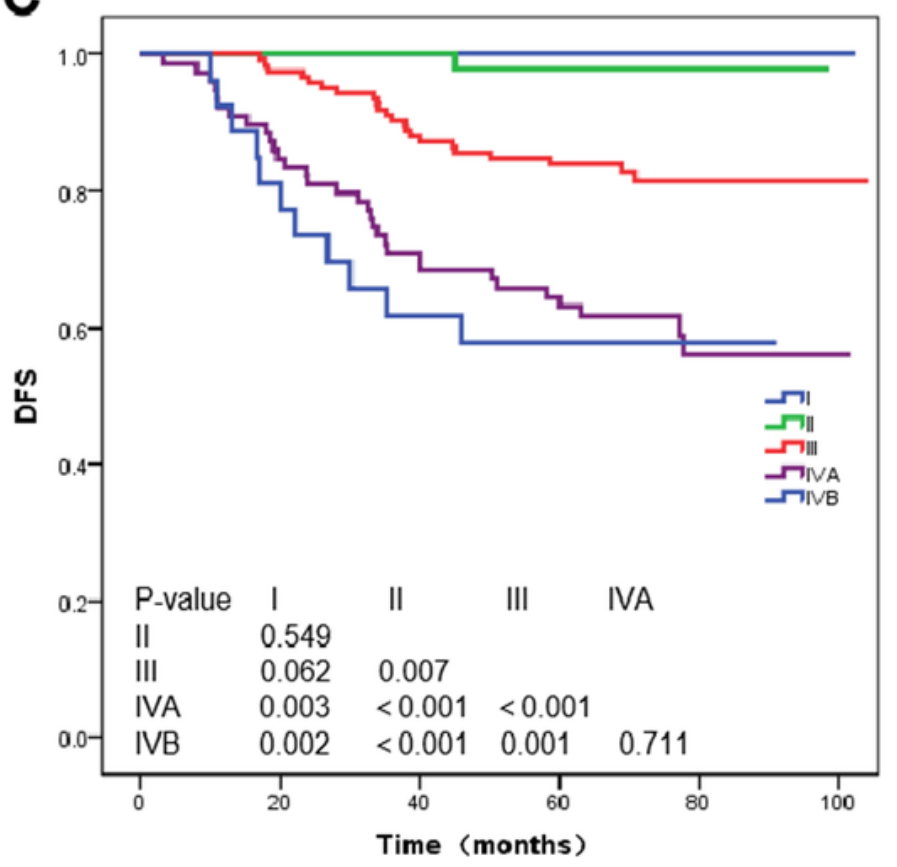

B

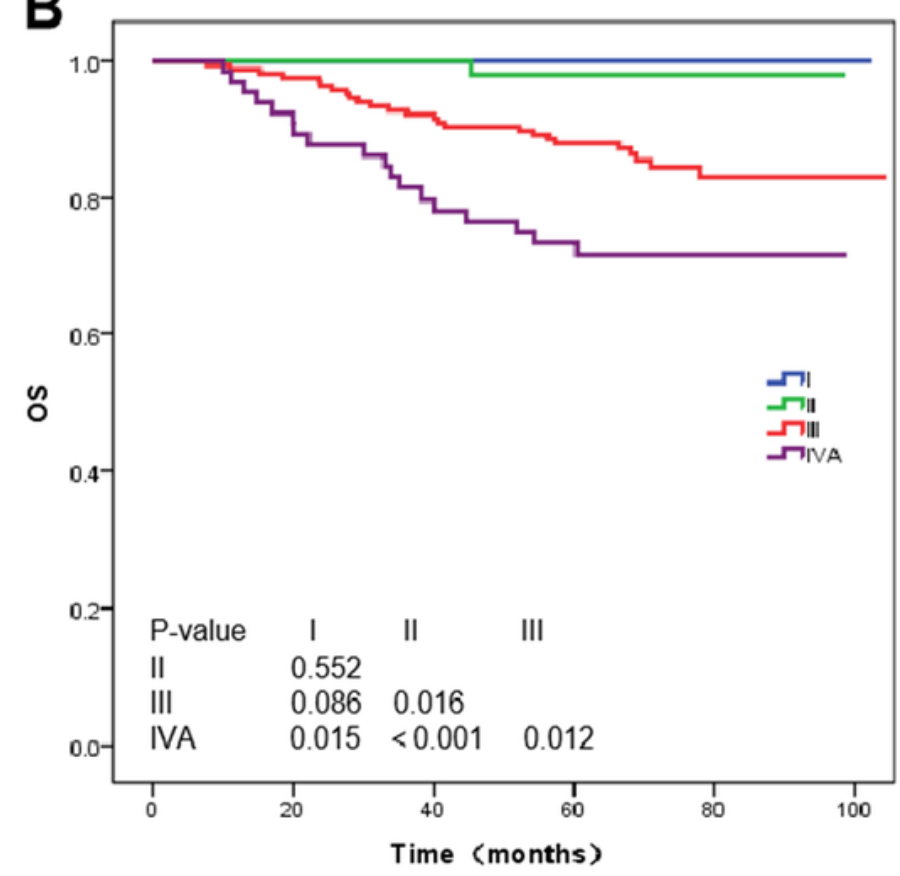

D

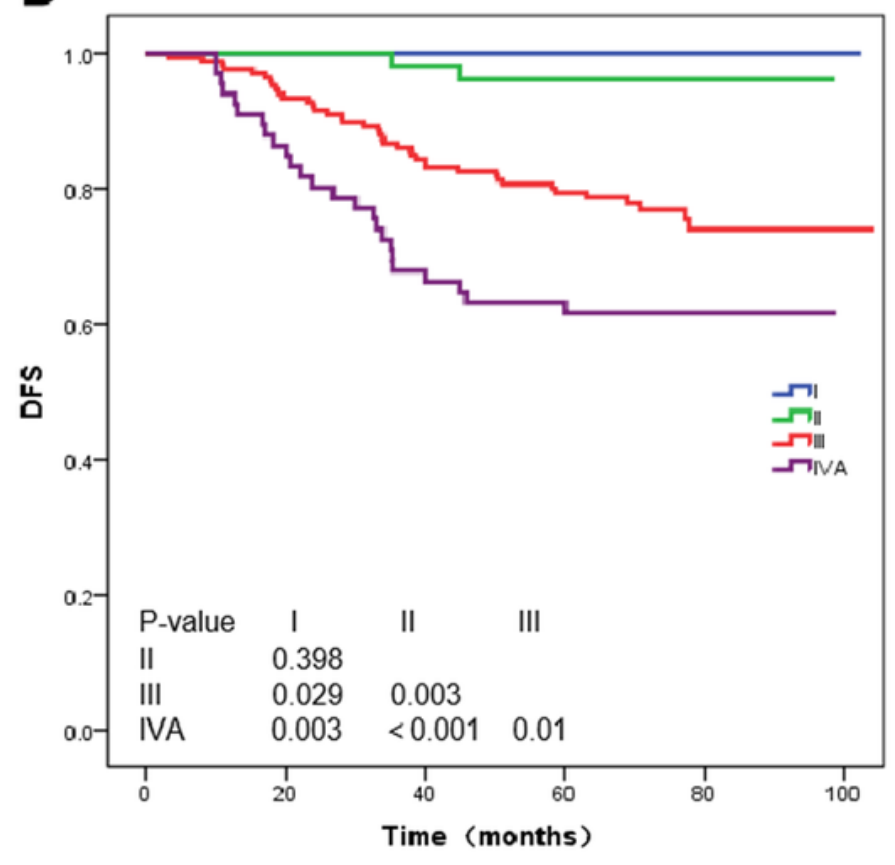

\section{Figure 3}

Overall survival $(A, B)$ and disease-free survival $(C, D)$ for each clinical stage in the 7th $(A, C)$ and 8th editions $(B, D)$. 

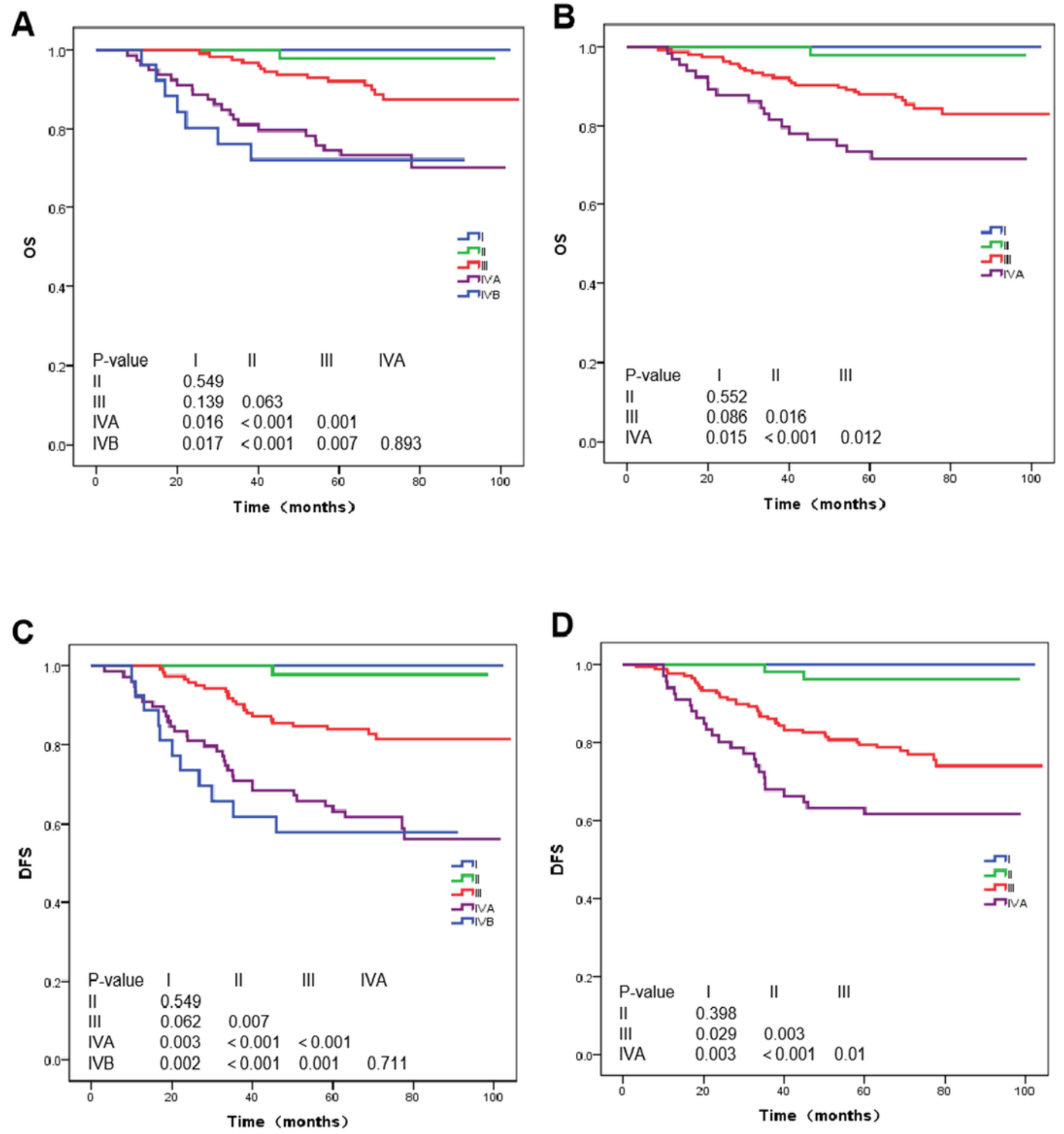

\section{Figure 3}

Overall survival $(A, B)$ and disease-free survival $(C, D)$ for each clinical stage in the 7th $(A, C)$ and 8th editions $(B, D)$. 